Review

\title{
Oral health in patients with COVID-19: a literature review
}

\author{
Nina E. Novozhilova ${ }^{1}$, Anna V. Pianzina ${ }^{2}$, Victoria A. Korol ${ }^{1}$ \\ ${ }^{1}$ Sechenov University, Moscow, Russia \\ ${ }^{2}$ Moscow Regional Research and Clinical Institute, Moscow, Russia
}

Received 1 December 2020, Revised 16 March 2021, Accepted 20 May 2021

(C) 2020, Novozhilova N.E., Pianzina A.V., Korol V.A.

(C) 2020, Russian Open Medical Journal

Abstract: This article reviews the most common oral health problems, which could be associated with coronavirus disease 2019 (COVID19). Several reports were published, which described various oral manifestations of COVID, including dysgeusia, petechiae, candidiasis, traumatic ulcers, herpesvirus infection, geographic tongue, thrush like ulcers, among others. Alterations of smell and taste seem to be the most common manifestations of COVID in the orofacial area, which could be directly related to the effect of the virus. Other oral conditions seem to be secondary to the decrease of host defense, or else caused by the drugs and intensive care used in the treatment of COVID-19.

Keywords: COVID-19, oral manifestations, dysgeusia.

Cite as Novozhilova NE, Pianzina AV, Korol VA. Oral health in patients with COVID-19: a literature review. Russian Open Medical Journal 2021 ; 10 : e0212.

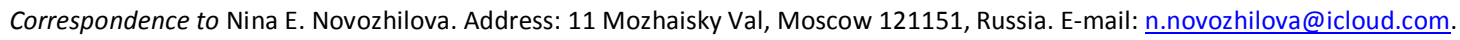

\section{Introduction}

The first cases of a respiratory disease caused by a new coronavirus were reported in China (Wuhan, province Hubei) in December 2019. Later a dramatic increase in the number of cases was observed in China and worldwide, and in March 2020 the World Health Organization (WHO) declared coronavirus disease 2019 (COVID-19) outbreak a pandemic disease. By mid-June 2020, over 8,000,000 cases of the disease have been confirmed with over 430,000 deaths. 'Coronavirus disease 2019 (COVID-19)' is the official name of this disease, announced by World Health Organization (WHO), and the virus is termed 'Severe acute respiratory syndrome coronavirus 2 (SARS-CoV-2)' [1].

The initial phase of any viral infection is the binding of viral particles to the membrane receptors of the host cells. Receptor recognition is, therefore, an important determinant of the cell and tissue tropism of a virus [2]. According to the current knowledge, SARS-CoV-2 is first inhaled and then it binds to the epithelial cells in the nasal cavity where replication starts. It has been shown that angiotensin-converting enzyme-2 (ACE2) is the main receptor for both SARS-CoV-2 and SARS-CoV $[3,4]$. The results of the in vitro studies of SARS-CoV indicated that the ciliated cells were primary cells infected in the conducting airways $[3,4]$. Considering the phylogenetic similarity between SARS-CoV and SARS-CoV-2 [5], which share more than $70 \%$ sequence identity in the $S$ protein, and both engage ACE2 [2], it is possible that ciliated cells could be also primarily infected by SARS-CoV-2. However, betacoronaviruses, to which the SARS-CoV-2 belongs, do not limit their presence to the respiratory tract, they also are capable of invading the central nervous system as was documented for the severe acute respiratory syndrome coronavirus (SARS-CoV) and Middle East respiratory syndrome coronavirus (MERS-CoV) [6]. Freni et al. (2020) investigated neurotropism and neuroinvasive status of the virus through the assessment of the sense of smell, taste, lacrimation, salivation and hearing [6]. They found that up to $92 \%$ of patients exhibited symptoms suggestive of the central nervous system involvement. Some other cells in the maxillofacial area with ACE2 on their membranes can be also infected. It was earlier reported that ACE2 receptors in the epithelial cells of the salivary glands of rhesus macaques were an initial target for the SARS coronavirus [7], which can be also relevant for SARS-CoV-2.

Many studies were aimed at describing clinical symptoms of COVID-19 [8-11]. It has been shown that the most prevalent symptoms included fever (66-99\%), coughing (37-82\%), fatigue (16-70\%), dyspnoea (8-55\%), and headache (8-37\%). As oral mucosa is an initial site of entry for SARS-CoV2, some oral manifestations might be the early symptoms of COVID-19 [6]. Several reports were published, which described various oral manifestations of COVID [12-17], including dysgeusia, petechiae, candidiasis, traumatic ulcers, herpes simplex virus type I (HSV-1) infection, geographic tongue, thrush-like ulcers, among others. However, it is still unclear whether these manifestations are the direct result of viral infection, or they are opportunistic infections caused by the decrease of host defence [17]. The purpose of the present article is to review the most common oral health problems, which could be associated with COVID-19.

\section{Olfactory and gustatory alterations}

Early papers published by Chinese authors reported few otolaryngological complaints, including olfactory and gustatory dysfunctions, in Asian patients [9-11]. In contrast to these articles, some authors from Europe revealed a high prevalence of anosmia and/or ageusia in patients with COVID-19 [8-14]. These differences could be attributed to the affinity of different viral strains for 
different tissues and the individual genetic differences between patients from various parts of the world.

A multicentre study aiming at studying otolaryngological manifestations of COVID-19 was conducted in four European countries (Belgium, France, Spain, Italy). The study included 417 patients with laboratory-confirmed mild-to-moderate COVID-19 infection from 12 European hospitals. The clinical outcomes assessed included general and otolaryngological symptoms. For the latter, the patients completed several olfactory and gustatory questionnaires. It was shown that $85.6 \%$ and $88.0 \%$ of patients reported olfactory and gustatory dysfunctions, respectively $[8,14]$. Ageusia was present in $28 \%$ of cases in the study by Sarker et al. (2010) who retrieved tweets using COVID-19-related keywords and performed semi-automatic filtering to curate self-reports of positive-tested users [8]. Freni et al. (2020) assessed 50 patients with laboratory-confirmed COVID-19 and found that 92\% of patients had olfactory dysfunction related to the infection, and $70 \%$ of patients reported gustatory disorders [6]. A recent crosssectional survey of 108 patients with confirmed COVID-19 in found that dysgeusia was present in $47.2 \%$ of cases [18].

The possible pathophysiological mechanisms leading to the olfactory and gustatory dysfunctions in the COVID-19 infection might be associated with the tropism of the SARS-Cov-2 to the olfactory cells and epithelial cells of the tongue [19], on which ACE2 receptor is highly expressed [20]. Further studies are needed to investigate the character and the exact etiology of the olfactory and gustatory dysfunctions in patients with COVID-19. Another possible reason that can contribute to taste disturbances is the change in the quantity and composition of saliva [21]. Salivary alterations in COVID-19 are discussed in the next section of the review. Generally, according to the current literature, sudden anosmia or ageusia should be recognized as possible symptoms of the COVID-19 infection.

\section{Salivary alterations}

It has been shown that ACE2-positive salivary gland epithelial cells are early targets of SARS-CoV in nonhuman primates and that salivary gland functions may be affected at an early stage of the disease [7]. In the study by To et al. (2020) SARS-CoV2 virus was detected in the self-collected saliva of $91.7 \%(11 / 12)$ of patients, and viral culturing confirmed live viruses in $25 \%$ (3/12) of patients [22]. These findings suggest that oral symptoms may occur due to salivary alterations in patients with COVID-19. A survey of patients with confirmed COVID-19 in Wuhan found that $46 \%$ of the patients reported dry mouth as one of their symptoms [18]. In another study, $32 \%$ of patients complained of dry mouth disorders, and, importantly, the onset of symptoms was earlier than the symptoms related to COVID-19 [6]. Thus, the presence of xerostomia (hyposalivation) or other salivary alterations in COVID19 patients should be evaluated, treated, and monitored in order to prevent the complications associated with the changes in quality and quantity of saliva [23].

\section{Oral mucosa lesions}

According to Galván Casas (2020), pseudo-chilblain and vesicular lesions on the skin may be useful indicators of the COVID19. These lesions should be differentiated from drug reactions as the patients with these presentations had more severe disease and received more drugs [24]. It is possible that similar lesions can develop on the mucous membranes of COVID-19 patients. Several case reports have been published describing various lesions on the oral mucosa of patients with COVID-19 [12-16].

In the report by Martín Carreras-Presas et al. (2020), three cases were presented: in two cases, there was a suspicion of COVID-19, and one case was with a confirmed infection. In all three cases, oral manifestations included ulcers or blisters, developing during the period of isolation [15]. The first patient was a 56-year-old male who complained of asthenia and fever for two days, hyposmia, dysgeusia, and pain in his palate. According to a photo, the lesions resembled secondary herpetic stomatitis, however, the patient did not have such lesions before. After ten days of Valaciclovir $500 \mathrm{mg}$ intake and the use of topical antiseptics with chlorhexidine and hyaluronic acid, there was full healing of the lesions. The second patient was a 58-year-old male with diabetes and hypertension. He also complained of pain in the palate, and a photo showed multiple small ulcers on his palate with unilateral affection. The patient reported no previous history of herpetic infection.

An antiseptic mouthwash was prescribed, and the lesions resolved within one week. The third patient was a 65-year-old female with obesity and hypertension. She complained of high fever, diarrhea, and pain in her tongue. She was diagnosed with bilateral pneumonia due to SARS CoV-2 infection and treated in the hospital with corticosteroids and antiviral drugs (Lopinavir 200 $\mathrm{mg}$, Ritonavir $50 \mathrm{mg}$, Hydroxychloroquine $200 \mathrm{mg}$ ). The lesions on the oral mucosa appeared a week after she was discharged from the hospital. These were blisters in the internal lip mucosa and desquamative gingivitis. Hyaluronic acid and chlorhexidine mouthwash were prescribed, and the lesions improved within three days. The authors pointed out that all three patients complained of pain, oral ulcers, or blisters before seeking medical help. They also hypothesized that oral lesions were often misdiagnosed in patients with COVID-19 due to the lack of intraoral examinations, and due to the severity of other manifestations [15].

After the initial article, several letters to the editor were published in different journals with a criticism of this case report. Sinadinos and Shelswell (2020) considered the first two cases described by Martín Carreras-Presas et al. (2020), to be herpetic lesions, and the last case, with lip blister and desquamative gingivitis, to be an erythema multiforme [25]. An increased number of cases of herpes zoster in patients with COVID-19 was also reported in a nationwide study of dermatological manifestations of COVID-19 in Spain [24]. Al-Khatib (2020) hypothesized that fear and emotional stress were the underlying causes that triggered herpetic lesions on the palate of the first two patients. Furthermore, accordingly, desquamative gingivitis and lip blisters in the third patient could not be considered the oral manifestations of COVID-19, as they appeared one month after the initial infection. He stated that if there was any association between oral ulcers and infection with SARS-CoV-2, it would have been reported by the thousands of symptomatic patients who have been affected by the disease because oral ulcers are very painful and interfere with chewing, swallowing and speaking [26]. On the basis of his observations, Vieira (2020) hypothesized that mild cases of COVID-19 may not show any oral manifestations [27].

Amorim et al. (2020) reported oral manifestations (geographic tongue and a persistent white plaque on the tongue dorsum) in a 67-year-old Caucasian man with confirmed COVID-19. The patient initially complained of hypogeusia and also reported severe 
comorbidities (coronary disease, hypertension, autosomal dominant polycystic kidney disease, and kidney transplant, with regular intake of immunosuppressants and Enoxaparin sodium (Clexane $20 \mathrm{mg} /$ day)). As chest computed tomography evidenced pneumonia, the patient was admitted to the hospital, intubated and treated with Hydroxychloroquine sulfate (Reuquinol ${ }^{\circledR}$, $400 \mathrm{mg} /$ day), Ceftriaxone sodium (2g/day), and Azithromycin (Zitromax ${ }^{\otimes} 500 \mathrm{mg} /$ day) for seven days. A persistent white plaque developed on the tongue dorsum. It was treated with intravenous Fluconazole (Zoltec ${ }^{\circledast} 200 \mathrm{mg} / 100 \mathrm{~mL}$, one bag a day for ten days) and oral nystatin $(100,000 \mathrm{IU} / \mathrm{mL}, 8 / 8 \mathrm{~h}$, for 30 days), but no regression was observed. In addition to the white plaque, the dentist also observed multiple pinpoint yellowish ulcers in the tongue dorsum resembling herpetic recurrent oral lesions [17]. The patient was discharged from the hospital and kept on the antifungals. Chlorhexidine digluconate $(0.12 \%)$ alcohol-free mouth rinse and daily applications of $1 \%$ hydrogen peroxide were also prescribed. Two weeks after the first oral examination, the white lesions on the tongue dorsum showed almost complete resolution and the patient presented an asymptomatic geographic tongue. The authors supported the argument that these oral conditions could be secondary to the deterioration of systemic health or due to treatments for COVID-19 [17].

In a case report by Chaux-Bodard (2020) a 45-years-old female patient presented with an irregular ulcer on the dorsal side of the tongue [12]. Before the ulcer development, there was a $24 \mathrm{~h}$ painful inflammation of a tongue papilla, followed by $24 \mathrm{~h}$ of the erythematous macula. After ten days, the ulcer completely healed without any scarring. COVID-19 in this patient was confirmed by a positive nasopharyngeal deoxyribonucleic acid (DNA) test on day 8. The authors consider this irregular oral ulcer an inaugural symptom of Covid-19, which needs to be proven in larger cohorts of patients [12].

Acute necrotizing gingivitis in a patient with COVID-19 was described in a report by Patel and Wooley (2020) [27]. The 35year-old female patient complained of fever for 3 days before oral symptoms (fever, halitosis, intense gingival pain, and bleeding). An intra-oral examination confirmed severe halitosis, generalized erythematous and edematous gingivae, and necrotic interdental papillae in both the maxillary and mandibular labial sextants. The symptoms subsided after 5 days of metronidazole $400 \mathrm{mg}$ three times daily and $0.12 \%$ chlorhexidine mouthwash twice daily. The author hypothesized that acute necrotizing gingivitis could be triggered by the decrease in host defense and increase in the numbers of Prevotella intermedia, Streptococci, Fusobacterium, Treponema, and Veillonella common in patients with COVID-10 [28] $P$. intermedia is considered to be an important species for acute periodontal lesions, and it constitutes a large proportion of bacteria found in necrotizing periodontal lesions together with Fusobacterium and Treponema [29].

On the whole, the aforementioned reports suggested the presence of some oral mucosal alterations in patients with COVID19. However, on the other hand, no oral ulcerations or necrotic lesions were reported in many other studies devoted to the documentation of COVID symptoms [8]. No such manifestations were described even in the studies, devoted to dysgeusia, while ulcerations and blisters of the oral cavity are highly likely to be reported, noted and documented by any researcher interested in evaluating dysgeusia [26]. Therefore, although oral health of COVID-19 patients can be affected by the infection, there is still doubt whether these manifestations could be a typical pattern, which results directly from the viral infection. Some oral conditions could be aggravated by SARS-CoV-2 due to its indirect complex effect, as well as intensified therapeutic methods, and multi-drug treatment [30].

\section{The effects of COVID-19 treatment on oral health}

During the outbreak, some potential antiviral drugs are being urgently administered to patients with COVID-19 [31] World Health Organization recently commenced Solidarity trial to compare four treatment options against the standard of care and to assess their relative effectiveness against COVID-19. The tested drugs included remdesivir, chloroquine/hydroxychloroquine, combined lopinavir and ritonavir, and interferon- $\beta$ [32,33]. However, an effective and safe pharmacological agent against COVID-19 was not found yet [30], while the potential ones are related to various adverse reactions, including oral lesions [34].

Remdesivir is an experimental drug, an adenosine analog that has a broad-spectrum antiviral activity against several viruses including MERS and SARSCoV-1. The information on oral healthrelated adverse reactions to this drug is lacking. The most common adverse events reported during the use of remdesivir in patients with COVID-19 include rash, hypotension, diarrhea, abnormal liver function, and renal impairment [35].

Chloroquine is approved to treat malaria and rheumatoid arthritis. While it has previously been tested in vitro against several viruses, including SARS, and found to inhibit growth, no benefit was seen in animal models [32]. The following adverse effects in the maxillofacial area have been reported for chloroquine: alopecia, bleaching of hair, blue-gray pigmentation of the skin, oral mucosa, and hard palate $[34,36]$. Hydroxychloroquine is a less toxic metabolite of chloroquine. Its adverse effects related to oral mucosa also include pigmentary changes (although they are uncommon, ranging between $0.1 \%$ and 1\%) [37] However, on 17 June 2020, WHO announced that the hydroxychloroquine arm of the Solidarity Trial was being stopped as hydroxychloroquine did not result in the reduction of mortality of hospitalized COVID-19 patients when compared with the standard of care.

Both lopinavir and ritonavir are protease inhibitors, approved for the treatment of HIV, combined in one drug called Kaletra. It can provide a reduction of the viral load, the severity, adverse clinical outcomes, and potentially reduce death rates in patients with SARS [38]. Oral-health related side effects of ritonavir may include dysgeusia (5-17\%), circumoral paresthesia (0-6.7\%), pharyngitis (0-2\%) and throat irritation (0.8-2.8\%) [39]. Lopinavir is an experimental drug with adverse effects, including diarrhea, nausea, vomiting, headache, abdominal pain, asthenia, and dyspepsia (more than $5 \%$ of patients). Besides, patients whose immune system responds to antiretroviral therapy may develop an inflammatory response to indolent or residual opportunistic infections.

Interferon alfa/beta, well-known for their antiviral activity [32], reduces the severity of COVID-19 disease, potentially improving survival rate. It decreases symptoms of severe respiratory illness, such as COVID-19 related pneumonia, and can support improvements in lung function. Interferon's more common side effect related to oral medicine is dry mouth, which can result in frequent cases of oral thrush [30]. Other oral healthrelated adverse effects include pharyngitis (1-31\%), dysgeusia (1$24 \%)$, dry mouth (1-28\%), face edema (1-10\%), and gingivitis (1- 
14\%) [40]. Dyspepsia, hypersalivation, thirst, esophagitis, hyperesthesia of the tongue, discoloration of the oral mucosa, oral pain, gingival bleeding, and gingival hyperplasia have been reported rarely [41].

A wide range of antibiotics, used in COVID-19 patients with multiple-organ dysfunctions to prevent bacterial complications, could have significant effects on the subtle balance of microorganisms, leading to further health impairments [42]. As a result of intense pharmacotherapy, some patients even after full recovery from COVID-10 may suffer from oral problems associated with soft tissues lesions, salivary flow, neurological-based oral sensations, etc. [30].

Intensive care, including external ventilation and blood oxygenation, could also adversely affect oral health in severely ill hospitalized patients. Advanced medical care, intubation, tracheostomy, external ventilation, as well as mouth breathing, a lack of mouth care, and hyposalivation can lead to rapid oral health deterioration and subsequent complications, affecting also the lower respiratory tract [31]. To prevent these complications, oral care with chlorhexidine have been used. However, a recent systematic review concluded that it is best, for now, to avoid using chlorhexidine in this case given the absence of clear evidence of benefit and the possible suggestion of harm (potentiate the development of intensive care unit-acquired pneumonia) [43].

\section{Conclusion}

In COVID-19 patients, there is a range of oral signs and symptoms, including dysgeusia, petechiae, candidiasis, traumatic ulcers, HSV-1 infection, geographic tongue, thrush-like ulcers, which are possibly associated with SARS-Cov-2 infection. The overall impact of COVID-19 on oral health seems to be multidirectional, immune-related, and most probably indirect, acting through various routes, reflecting the pathological nature of coronavirus respiratory track invasion via mucous membranes [30]. Alterations of smell and taste seem to be the most common manifestations of COVID in the orofacial area, which could be directly related to the effect of the virus. Other oral conditions seem to be secondary to the decrease of host defense or due to the drugs and intensive care used in the treatment of COVID-19. Further research is essential: it is particularly crucial to study the prevalence and causes of COVID-19 oral manifestations.

\section{Acknowledgments}

None.

\section{Conflict of interest}

The authors declare no conflicts of interest.

\section{References}

1. Lu R, Zhao X, Li J, Niu P, Yang B, Wu H, et al. Genomic characterisation and epidemiology of 2019 novel coronavirus: implications for virus origins and receptor binding. Lancet 2020; 395(10224): 565-574. http://doi.org/10.1016/S0140-6736(20)30251-8.

2. Wang $Q$, Zhang $Y$, Wu L, Niu S, Song $C$, Zhang Z, et al. Structural and Functional Basis of SARS-CoV-2 Entry by Using Human ACE2. Cell 2020; 181(4): 894-904.e9. https://doi.org/10.1016/i.cell.2020.03.045.

3. Mason RJ. Pathogenesis of COVID-19 from a cell biology perspective. Eur Respir J 2020; 55(4): 2000607. https://doi.org/10.1183/13993003.00607-2020.
4. Sims AC, Baric RS, Yount B, Burkett SE, Collins PL, Pickles RJ. Severe Acute Respiratory Syndrome Coronavirus Infection of Human Ciliated Airway Epithelia: Role of Ciliated Cells in Viral Spread in the Conducting Airways of the Lungs. J Virol 2005; 79(24): 15511-15524. https://doi.org/10.1128/jvi.79.24.15511-15524.2005.

5. Chu H, Chan JF, Yuen TT, Shuai H, Yuan S, Wang Y, et al. Comparative tropism, replication kinetics, and cell damage profiling of SARS-CoV-2 and SARS-CoV with implications for clinical manifestations, transmissibility, and laboratory studies of COVID-19: an observational study. Lancet Microbe 2020; 1(1): e14-e23. http://doi.org/10.1016/S2666-5247(20)30004-5.

6. Freni F, Meduri A, Gazia F, Nicastro V, Galletti C, Aragona P, et al. Symptomatology in head and neck district in coronavirus disease (COVID-19): A possible neuroinvasive action of SARS-CoV-2. Am J Otolaryngol 2020; 41(5): 102612 https://doi.org/10.1016/j.amjoto.2020.102612.

7. Liu L, Wei Q, Alvarez X, Wang H, Du Y, Zhu H, et al. Epithelial Cells Lining Salivary Gland Ducts Are Early Target Cells of Severe Acute Respiratory Syndrome Coronavirus Infection in the Upper Respiratory Tracts of Rhesus Macaques. J Virol 2011; 85(8): 4025-4030. https://doi.org/10.1128/ivi.02292-10.

8. Sarker A, Lakamana S, Hogg-Bremer W, Xie A, Al-Garadi MA, Yang Y-C. Self-reported COVID-19 symptoms on Twitter: An analysis and a research resource. J Am Med Inform Assoc 2020; 27(8): 1310-1315. https://doi.org/10.1093/jamia/ocaa116.

9. Guan WJ, Ni ZY, Hu Y, Liang WH, Ou CQ, He JX, et al. Clinical characteristics of coronavirus disease 2019 in China. N Engl J Med 2020; 382(18): 1708-1720. https://doi.org/10.1056/neimoa2002032.

10. Chen J, Qi T, Liu L, Ling Y, Qian Z, Li T, et al. Clinical progression of patients with COVID-19 in Shanghai, China. J Infect 2020; 80(5): e1-e6. https://doi.org/10.1016/i.jinf.2020.03.004.

11. Huang $C$, Wang $Y$, Li X, Ren L, Zhao J, Hu Y, et al. Clinical features of patients infected with 2019 novel coronavirus in Wuhan, China. Lancet 2020; 395(10223): 497-506. https://doi.org/10.1016/s01406736(20)30183-5.

12. Chaux-Bodard A-G, Deneuve S, Desoutter A. Oral manifestation of Covid-19 as an inaugural symptom? J Oral Med Oral Surg 2020; 26(2): 18. https://doi.org/10.1051/mbcb/2020011.

13. De Maria A, Varese P, Dentone C, Barisione E, Bassetti M. High prevalence of olfactory and taste disorder during SARS-CoV-2 infection in outpatients. J Med Virol 2020; 92(11): 2310-2311. https://doi.org/10.1002/jmv.25995.

14. Lechien JR, Chiesa-Estomba CM, De Siati DR, Horoi M, Le Bon SD, Rodriguez $A$, et al. Olfactory and gustatory dysfunctions as a clinical presentation of mild-to-moderate forms of the coronavirus disease (COVID-19): a multicenter European study. Eur Arch Otorhinolaryngol 2020; 277(8): 2251-2261. https://doi.org/10.1007/s00405-020-059651.

15. Martín Carreras-Presas C, Amaro Sánchez J, López-Sánchez AF, JanéSalas E, Somacarrera Pérez ML. Oral vesiculobullous lesions associated with SARS-CoV-2 infection. Oral Dis 2020; 27 Suppl 3: 710-712. https://doi.org/10.1111/odi.13382.

16. Putra BE, Adiarto S, Dewayanti SR, Juzar DA. International Journal of Infectious Diseases Viral exanthem with "Spins and needles sensation" on extremities of a COVID-19 patient: A self-reported case from an Indonesian medical frontliner. Int J Infect Dis 2020; 96: 355-358. https://doi.org/10.1016/j.jijid.2020.05.020.

17. Amorim Dos Santos J, Normando AGC, Carvalho da Silva RL, De Paula RM, Cembranel AC, Santos-Silva AR, et al. Oral mucosal lesions in a COVID-19 patient: new signs or secondary manifestations? Int J Infect Dis 2020; 97: 326-328. https://doi.org/10.1016/i.ijid.2020.06.012.

18. Chen L, Zhao J, Peng J, Li X, Deng X, Geng Z, et al. Detection of 2019nCoV in Saliva and Characterization of Oral Symptoms in COVID-19 Patients. Cell Prolif 2020; 53(12): e12923. https://doi.org/10.1111/cpr.12923. 
19. Brann DH, Tsukahara T, Weinreb C, Lipovsek M, Van den Berge K, Gong $B$, et al. Non-neuronal expression of SARS-CoV-2 entry genes in the olfactory system suggests mechanisms underlying COVID-19associated anosmia. Sci Adv 2020; 6(31): eabc5801. https://doi.org/10.1126/sciadv.abc5801.

20. Xu H, Zhong L, Deng J, Peng J, Dan H, Zeng X, et al. High expression of ACE2 receptor of 2019-nCoV on the epithelial cells of oral mucosa. Int J Oral Sci 2020; 12(1): 8. https://doi.org/10.1038/s41368-020-0074-x.

21. Matsuo R. Role of Saliva in the Maintenance of Taste Sensitivity. Crit Rev Oral Biol Med 2000; 11(2): 216-229. https://doi.org/10.1177/10454411000110020501.

22. To KK, Tsang OT, Yip CC, Chan KH, Wu TC, Chan JM, et al. Consistent detection of 2019 novel coronavirus in saliva. Clin Infect Dis 2020; 71(15): 841-843. https://doi.org/10.1093/cid/ciaa149.

23. Vinayachandran D, Balasubramanian S. Is Gustatory Impairment the First Report of an Oral Manifestation in COVID-19? Oral Dis 2020; 27 Suppl 3: 748-749. https://doi.org/10.1111/odi.13371.

24. Galván Casas $C$, Català A, Carretero Hernández G, Rodríguez-Jiménez $P$, Fernández Nieto D, Rodríguez-Villa Lario A, et al. Classification of the cutaneous manifestations of COVID-19: a rapid prospective nationwide consensus study in Spain with 375 cases. Br J Dermatol 2020; 183(1): 71-77. https://doi.org/10.1111/bjd.19163.

25. Sinadinos A, Shelswell J. Oral ulceration and blistering in patients with COVID-19. Evid Based Dent 2020; 21(2): 49. https://doi.org/10.1038/s41432-020-0100-z.

26. Al-Khatib A. Oral manifestations in COVID-19 patients. Oral Dis 2020; 27 Suppl 3: 779-780. https://doi.org/10.1111/odi.13477.

27. Vieira AR. Oral manifestations in coronavirus disease 2019 (COVID-19). Oral Dis 2021; 27 Suppl 3: 770. https://doi.org/10.1111/odi.13463.

28. Chakraborty S. SARS-Cov2 enables anaerobic bacteria (Prevotella, et al.) to colonize the lungs disrupting homeostasis-symptoms (ARDS, septic shock, blood clots, arterial stroke) finds resonance, with key differences, in the 'forgotten disease' Lemierre. OSF Prepr 2020. https://doi.org/10.31219/osf.io/usztn.

29. Patel J, Woolley J. Necrotizing periodontal disease: oral manifestation of COVID-19. Oral Dis 2021; 27 Suppl 3: 768-769. https://doi.org/10.1111/odi.13462.

30. Dziedzic A, Wojtyczka R. The impact of coronavirus infectious disease 19 (COVID-19) on oral health. Oral Dis 2021;27 Suppl 3: 703-706. https://doi.org/10.1111/odi.13359.

31. Ahn DG, Shin HJ, Kim MH, Lee S, Kim HS, Myoung J, et al. Current status of epidemiology, diagnosis, therapeutics, and vaccines for novel coronavirus disease 2019 (COVID-19). J Microbiol Biotechnol 2020; 30(3): 313-324. https://doi.org/10.4014/imb.2003.03011.

32. Mahase E. Covid-19: what treatments are being investigated? BMJ 2020; 368: m1252. https://doi.org/10.1136/bmj.m1252.

33. Sayburn A. Covid-19: trials of four potential treatments to generate "robust data" of what works. BMJ 2020; 368: m1206. https://doi.org/10.1136/bmj.m1206.

34. Godinho GV, Paz ALLM, de Araújo Gomes EPA, Garcia CL, Volpato LER. Extensive hard palate hyperpigmentation associated with chloroquine use. $\mathrm{Br} J$ Clin Pharmacol 2020; 86(11): 2325-2327. https://doi.org/10.1111/bcp.14313.

35. Singh AK, Singh A, Singh R, Misra A. Remdesivir in COVID-19: A critical review of pharmacology, pre-clinical and clinical studies. Diabetes Metab Syndr 2020; 14(4): 641-648. https://doi.org/10.1016/i.dsx.2020.05.018.

36. Gallo CB, Luiz AC, Ferrazzo KL, Migliari DA, Sugaya NN. Drug-induced pigmentation of hard palate and skin due to chronic chloroquine therapy: Report of two cases. Clin Exp Dermatol 2009; 34(7): e266e267. https://doi.org/10.1111/j.1365-2230.2008.03185.x.

37. Misra DP, Gasparyan AY, Zimba O. Benefits and adverse effects of hydroxychloroquine, methotrexate and colchicine: searching for repurposable drug candidates. Rheumatol Int 2020; 40(11): 1741-1751. https://doi.org/10.1007/s00296-020-04694-2.
38. Chu CM, Cheng VC, Hung IF, Wong MM, Chan KH, Chan KS, et al. Role of lopinavir/ritonavir in the treatment of SARS: Initial virological and clinical findings. Thorax 2004; 59(3): 252-256. https://doi.org/10.1136/thorax.2003.012658.

39. Cai J, Xiao J, Zhang Q. Side effects and tolerability of post-exposure prophylaxis with zidovudine, lamivudine, and lopinavir/ritonavir: a comparative study with HIV/AIDS patients. Chin Med J (Engl) 2014; 127(14): 2632-2636. https://pubmed.ncbi.nlm.nih.gov/25043080.

40. Cao B, Wang Y, Wen D, Liu W, Wang J, Fan G, et al. A Trial of LopinavirRitonavir in Adults Hospitalized with Severe Covid-19. N Engl J Med 2020; 382(19): 1787-1799. https://doi.org/10.1056/nejmoa2001282.

41. Khanna NR, Gerriets V. Interferon. 2021 Mar 25. In: StatPearls. Treasure Island (FL): StatPearls Publishing; 2021. https://pubmed.ncbi.nlm.nih.gov/32310392.

42. Jean SS, Lee PI, Hsueh PR. Treatment options for COVID-19: The reality and challenges. J Microbiol Immunol Infect 2020; (53): 436-443. https://doi.org/10.1016/j.jmii.2020.03.034.

43. Klompas M. Prevention of Intensive Care Unit-Acquired Pneumonia. Semin Respir Crit Care Med 2019; 40(4): 548-557. https://doi.org/10.1055/s-0039-1695783.

\section{Authors:}

Nina E. Novozhilova - PhD, Associate Professor, Department of Therapeutic Dentistry, Sechenov University, Moscow, Russia. http://orcid.org/0000-0002-1073-7693.

Anna V. Pianzina - PhD, Associate Professor, Department of Prosthetic Dentistry, Moscow Regional Research and Clinical Institute, Moscow, Russia. http://orcid.org/0000-0002-1492-7494.

Victoria A. Korol - PhD, Assistant Professor, Department of Therapeutic Dentistry, Sechenov University, Moscow, Russia. http://orcid.org/0000$\underline{0002-8587-7965 .}$ 